ESTUDOS RB:P

\title{
A expansão das fronteiras da educação pública superior: uma análise da experiência da Universidade Federal da Fronteira Sul em Laranjeiras do Sul
}

\author{
Naira Estela Roesler Mohr \\ Felipe Mattos Monteiro \\ Joaquim Gonçalves Costa \\ João Costa de Oliveira
}

\section{Resumo}

Pretende observar o processo de criação e consolidação da Universidade Federal da Fronteira Sul, no campus de Laranjeiras do Sul, Estado do Paraná, que desde sua origem vem propondo dispositivos de combate às desigualdades sociais e regionais. Situa o contexto de construção da Universidade, discorrendo sobre as estratégias utilizadas para garantir as condições de acesso e permanência no ensino superior, especialmente da população proveniente da escola pública. Busca também refletir em que medida as ações afirmativas estão conseguindo se materializar de forma efetiva no interior da instituição, a partir da análise dos dados acadêmicos do primeiro ano letivo. O diálogo resultante desses elementos aponta avanços, limites e muitos desafios, que deverão constar no debate permanente da construção política e pedagógica da Universidade.

Palavras-chave: universidade; ações afirmativas; escola pública. 


\section{Abstract}

The expansion of the frontiers of college public education: an analysis about the UFFS experience in Laranjeiras do Sul

This article intents to examine the creation process and the consolidation of the Federal University of Fronteira Sul (Universidade Federal da Fronteira Sul), Laranjeira do Sul Campus, Paraná, south Brazil. This University has presented mechanisms to combat social and regional differences. The text discusses the context of building the University, and the discoursed strategies used to ensure the conditions for access and permanence in higher education, especially of the students from public schools. It also seeks to reflect the analysis of scholarly data of the first academic year and how the affirmative actions are getting effectively materialize inside the institution. The resulting dialog of these elements shows a progress, limits and many challenges should be included in the permanent debate of political and pedagogical construction of University.

Keywords: university; affirmative actions; public school.

\section{Introdução}

Na segunda semana do mês de fevereiro de 2011, no primeiro processo de Formação Acadêmica do Campus de Laranjeiras do Sul, um dos cinco campi da recém-criada Universidade Federal da Fronteira Sul (UFFS), foram colocados em evidência vários apontamentos acerca da avaliação do primeiro ano letivo da Universidade, entre eles uma angústia em relação ao baixo aproveitamento acadêmico.

Nas falas de vários professores destaca-se a preocupação de que muitos estudantes chegaram ao curso universitário com defasagens de conceitos básicos nas mais diversas áreas do conhecimento, lacunas que, segundo esses professores, são provenientes do ensino médio. Ao discorrer sobre esta constatação, emanaram algumas questões que precisam ser problematizadas: É possível afirmar, por serem, na sua grande maioria, alunos oriundos da escola pública, que apresentarão sérios limites na apropriação do conhecimento? Detectado este panorama, como estão sendo pensadas, elaboradas e experimentadas alternativas que possam tratar destas dificuldades? Em que medida é possível conciliar excelência acadêmica com o processo de democratização do ensino superior, tão anunciado e tão pouco difundido?

Este debate torna-se central, uma vez que a Universidade, desde sua origem, apresenta o compromisso com a inclusão, tendo buscado se 
afirmar como uma "universidade que estabeleça dispositivos de combate às desigualdades sociais e regionais, incluindo condições de acesso e permanência no ensino superior, especialmente da população mais excluída do campo e da cidade" (UFFS, 2010a).

Desta forma, é pretensão deste trabalho olhar para o processo instituído neste relativamente curto espaço de tempo, buscando muito mais do que detectar ou apontar a condição de aproveitamento, mas analisar em que medida as ações afirmativas estão se consolidando e encontrando base material para que se solidifiquem e se ampliem neste espaço. Outrossim, é preocupação permanente, além de criar possibilidades de acesso, refletir sobre as condições de permanência e de qualificação acadêmica, para que se caracterize como um processo de inclusão real, e não apenas formal.

A necessária intervenção através de políticas afirmativas para inclusão de acesso e permanência no ensino superior é reflexo-resultado das condições objetivadas na organização da materialidade social, que, ao mesmo tempo que se vê como uma possibilidade de enfrentamento da realidade perversa constituída, nos defronta com os limites que essa realidade impõe. São aspectos constructos das contradições, mas, no limiar da possibilidade e do limite, é preciso analisar esse processo.

Cabe retomar a discussão feita por Kuenzer (2006, p. 4) acerca das categorias de exclusão includente, destacando que muitas políticas educacionais incluem, mas, dada a sua desqualificação, são excludentes:

\begin{abstract}
Concordando com Oliveira [2004], que faz um estudo rigoroso dessa categoria nas obras de Marx, parte-se do pressuposto de que, no modo de produção capitalista, todas as formas de inclusão são sempre subordinadas, concedidas, porque atendem às demandas do processo de acumulação. Ou, como afirma o autor, o círculo entre exclusão e inclusão subordinada é condição de possibilidade dos processos de produção e reprodução do capital, sendo constitutivo lógico necessário das sociedades capitalistas modernas. Ou seja, são faces inseparáveis da mesma moeda.
\end{abstract}

\section{E conclui Kuenzer, transcrevendo texto de Oliveira:}

A sobrevivência das sociedades em que domina o modo de produção capitalista depende, necessariamente, da exclusão. Sob outro ângulo, entretanto, esta exclusão conta também com o passo da inclusão, mas a reinclusão do excluído já se dá sob uma nova perspectiva ontológica. O preço pago para que o princípio de síntese do capital seja capaz de abranger toda a realidade é torná-la disponível à sua lógica, ou seja, é preciso antes despojá-la de sua condição de complexidade e reduzi-la à simplicidade das determinações quantitativas da economia. (Oliveira, 2004, p. 23)

Para melhor percepção do contexto que pretendemos discutir, é preciso primeiro compreender de que forma foi se conquistando e organizando este espaço universitário. Para isso, pretende-se recuperar a trajetória percorrida no processo de construção, desde as primeiras ideias e movimentações que emergiram de uma necessidade concreta e 
embasadas num forte envolvimento popular até a oficialização da UFFS. Destaca-se o papel das organizações e movimentos sociais neste importante e intenso percurso, dando substância ao Projeto Institucional, e algumas práticas já realizadas.

Em seguida buscaremos observar o processo de criação dos cursos e suas turmas, trazendo elementos e mecanismos constituídos institucionalmente no esforço de promover ações afirmativas e capazes de colocar em foco permanente o olhar sobre os sujeitos em formação e sua relação com a cultura acadêmica. De forma mais específica, estaremos observando o Curso de Licenciatura em Educação do Campo a partir de um levantamento realizado com professores e acadêmicos acerca das dificuldades de aprendizagem apresentadas no primeiro ano letivo.

Em um terceiro momento, serão apresentados dados do perfil socioeconômico discente no primeiro ano de funcionamento no Campus Laranjeiras do Sul, refletindo sobre as possíveis mudanças observadas neste território com a chegada da Universidade. Pretende-se ainda avaliar em que medida estão articulados os princípios de inclusão com a realidade dos acadêmicos matriculados.

Por fim, objetivamos trazer e/ou recuperar elementos que possam contribuir com o planejamento estratégico de ação acadêmica, apontando avanços, limites e desafios que interferem na construção do projeto da Universidade numa perspectiva de alargamento das oportunidades.

\section{Território da UFFS - Campus de Laranjeiras do Sul-PR}

A cidade de Laranjeiras do Sul se localiza em uma mesorregião chamada de Cantuquiriguaçu, constituída por 20 municípios: Campo Bonito, Candói, Cantagalo, Catanduvas, Diamante do Sul, Espigão Alto do Iguaçu, Foz do Jordão, Goioxim, Guaraniaçu, Ibema, Laranjeiras do Sul, Marquinho, Nova Laranjeiras, Pinhão, Porto Barreiro, Quedas do Iguaçu, Reserva do Iguaçu, Rio Bonito do Iguaçu, Três Barras do Paraná e Virmond.

As últimas três décadas foram de intensas e importantes mudanças no espaço denominado Território Cantuquiriguaçu, que vão desde a implantação do agronegócio pelas multinacionais até a reconfiguração da propriedade privada no campo e nos assentamentos de reforma agrária, conquistados, em sua maioria, na pressão popular, por movimentos organizados. Essas mudanças promovidas pelo capitalismo agrário ou pelas forças sociais acontecem paralelamente, ao mesmo tempo. Disputam espaços, territórios materiais e imateriais, e constituem-se numa constante contradição que extrapola a escala regional, atingindo, por desdobramentos necessários, a escala nacional e internacional.

Como afirma Bernardo Mançano Fernandes (2008, p. 280),

Temos então uma disputa territorial entre capital e campesinato. As propriedades camponesas e capitalistas são territórios distintos, são totalidades diferenciadas, nas quais se produzem relações sociais diferentes, que promovem modelos divergentes de desenvolvimento. 
Territórios camponeses e territórios capitalistas como diferentes formas de propriedades privadas disputam o território nacional.

De um lado, as empresas multinacionais, amparadas nas parcerias com empresas-cooperativas tradicionais locais e com os órgãos oficiais da assistência técnica dos governos e seus programas, introduzem as relações capitalistas até os mais longínquos rincões. Subordinam grandes, médios e pequenos produtores a uma lógica nefasta de exploração e concentração de riquezas, por serem empresas detentoras da tecnologia.

De outro, uma multidão de excluídos desse mesmo sistema hegemônico no campo buscam a sustentabilidade e a sobrevivência por meio da organização social, retomando territórios, disputando a opinião pública, buscando novas matrizes tecnológicas e questionando os marcos legais de uma sociedade essencialmente liberal desde a primeira Constituição Brasileira de 1824. São movimentos contra-hegemônicos que se desenvolvem na periferia do sistema em uma condição extremamente vulnerável, pois muitas vezes absorvem para dentro de suas formas organizacionais as contradições presentes na sociedade capitalista e liberal que os circunda, o que os leva à inviabilidade, sobretudo econômica, apesar do esforço em se fazer um caminho em sentido oposto.

O caso do Território Cantuquiriguaçu não foge à regra. Aqui o processo de modernização da agricultura não gerou desenvolvimento no sentido mais completo, uma vez que não distribuiu riquezas nem criou condições materiais para uma vida de qualidade no campo. E nem podia ser diferente: as condições estavam postas nos princípios capitalistas da agricultura convencional, ou seja, a exploração e a concentração de todos os recursos nas mãos das multinacionais. O resultado inevitável foi o êxodo rural em larga escala, principalmente para além das fronteiras do Território.

Do ponto de vista social, a miséria avançou no campo e na cidade, medindo-se baixos Índices de Desenvolvimento Humano (IDH) em quase todos os municípios do Território, compondo assim, a partir da década de 1990, o obscuro mapa da fome. Isto fica bem claro no texto do Sumário Executivo do Diagnóstico Socioeconômico do Território:

O diagnóstico identificou 26.159 famílias pobres, ou seja, 41,87\% das famílias do território percebiam 1/2 salário mínimo per capita mensal (R\$ 72,50 ) em julho de 2000. A pobreza absoluta agrega-se aos indicadores de inadequação habitacional, captando uma outra dimensão da pobreza. O Censo Demográfico 2000 identificou que, no território, 31,71\% dos domicílios rurais não tinham acesso a água encanada; $72,25 \%$ dos domicílios urbanos e 91,66\% dos domicílios rurais encontravam-se na condição de inadequação quanto à destinação do esgoto sanitário; $94,16 \%$ do lixo rural não era coletado e 13,85\% dos domicílios não tinham acesso a energia elétrica. Esses percentuais dão uma medida da necessidade de adequação das moradias. Um outro dado, o déficit habitacional, mede a demanda por novas unidades, que, no território Cantuquiriguaçu, é da ordem de 5.342 moradias.

A taxa de mortalidade infantil, que mede o número de crianças que não sobrevivem ao primeiro ano de vida, em cada mil crianças nascidas 
vivas, apresenta-se, em todos os municípios, superior à taxa estadual $(20,3)$. A estrutura de atendimento médico-hospitalar é restrita; o território conta com dois pronto-atendimentos de 24 horas e com treze hospitais.

A taxa de analfabetismo da população acima de 15 anos de idade é de 14,4\%, superior à média do Paraná (9,0\%), o que reforça a necessidade de se enfrentar essa questão. A constatação de que quase $25 \%$ da população do território possui menos de 4 anos de estudos confirma a necessidade de intervir nas condições adversas que a impedem de alcançar patamares maiores de anos de estudos. (Conselho..., 2004, p. VIII-IX).

Contraditoriamente, os latifúndios se avolumaram. Grandes empresas passaram a controlar recursos naturais essenciais, como é o caso, por exemplo, das terras para a produção de florestas para extração de celulose, produção de gado ou de grãos, ou das águas do rio Iguaçu, controladas por companhias privadas de energia elétrica e/ou pelas ações privadas nas estatais, além dos setores de serviços importantes e rentáveis, como o de transportes por rodovias e ferrovias, que foram instalados no território com investimentos estatais, posteriormente privatizados, encarecendo significativamente o custo de produção.

A contradição apontada acima, expressa na disparidade social, converteu-se, na sequência, em convulsão social: conflito - sobretudo por terra.

Surgem as primeiras ocupações de terras na década de 1980 e, consequentemente, os grandes assentamentos de reforma agrária no final da década de 1990, trazendo uma grande transformação: estrutural, ao repartir a propriedade privada do latifúndio, que muitas vezes era adquirido de forma espúria, por grilagem e/ou favorecimentos diversos; social, incluindo pessoas beneficiárias da assistência social na ala produtiva, resgatando sua dignidade e, mais do que isto, ensinando-as o caminho das grandes conquistas pelo método das lutas de massas; e econômica, dinamizando a economia pelo simples retorno da população ao território, advinda com os acampamentos e assentamentos.

Vale lembrar que alguns municípios do Território tiveram repentinamente sua população triplicada, em função das ocupações promovidas pelo Movimento dos Trabalhadores Rurais Sem Terra (MST).

A partir daí, o novo "caldo social" sugeriu mudanças em todos os setores: na educação, com a introdução da noção de educação do campo; na cultura popular, a partir do resgate da identidade do camponês; e na política local, com a eleição de lideranças mais progressistas, ligadas aos movimentos sociais populares e às pastorais sociais da Igreja Católica.

Nesse contexto de produção e reprodução da vida, de grande massa de jovens filhos de assentados sem perspectivas claras de futuro, num campo transformado, minado pela hegemonia das transnacionais do agronegócio, e, por outro lado, de uma população urbana cada vez maior, com problemas cada vez mais desafiadores, como o desemprego ou o subemprego e a falta de infraestrutura, é que surgem os primeiros debates acerca da construção de uma universidade. 
Cientes desta necessidade, movimentos sociais como MST, Movimento dos Pequenos Agricultores (MPA), Sindicato dos Trabalhadores em Educação Pública do Paraná (APP), Federação Nacional dos Trabalhadores e Trabalhadoras na Agricultura Familiar (Fetraf) e algumas prefeituras da região iniciaram um extenso debate com o objetivo de viabilizar a instalação de uma universidade popular. Esta deveria ser comandada por um coletivo e, inicialmente, financiada por projetos dirigidos para a captação de recursos federais e estaduais, bem como por três ou quatro prefeituras locais.

Havia experiências que subsidiavam esse debate, como é o caso da Universidade de Mondragón, território basco cuja força cooperativa é referência mundial, e outras experiências em projetos de educação do campo desenvolvidas no Cantuquiriguaçu e outras regiões, como "Terra Solidária", "Saberes da Terra", "Pronera", "Lumiar" e outros que têm sido referência nas políticas públicas.

A cooperativa de Mondragón, detentora de aproximadamente 150 empresas, com tecnologia de ponta em diversas áreas e ramos, possui como um de seus pilares a sua própria universidade, responsável pela formação humana e técnica de seus quadros.

Esse projeto já contava com parcerias bem avançadas com os próprios bascos, com professores da Universidade Estadual de São Paulo e com o Instituto Brasileiro de Estudos Contemporâneos (Ibec), sob a coordenação do professor Dr. Paulo Alves de Lima Filho, que, mais tarde, por indicação do coletivo local, compôs a Comissão de Instalação da UFFS.

Esse debate iniciou-se ainda no primeiro semestre do ano de 2005, intensificando-se com reuniões periódicas de um coletivo com representações das prefeituras de Porto Barreiro, Rio Bonito do Iguaçu, Nova Laranjeiras, Candói e Laranjeiras do Sul e representantes dos movimentos sociais e entidades citados acima.

No primeiro semestre de 2006, porém, a partir de articulações com representantes da Via Campesina, observou-se que no Rio Grande do Sul e em Santa Catarina também acontecia forte mobilização em torno da conquista de uma universidade federal pública e gratuita para a mesorregião da grande fronteira do Mercosul. Optou-se então por agregar estes esforços em torno do movimento pró-universidade nos três Estados do Sul, compondo assim um movimento maior e mais completo.

Em princípio este movimento era carente de unidade, uma vez que cada Estado se articulava a partir de suas próprias forças políticas, sob diversas orientações, demandando sobremaneira a atenção do Ministério da Educação (MEC).

Foram realizados inúmeros debates, seminários e reuniões em diversos níveis - local, territorial, estadual e regional (mesorregional) e organizadas mobilizações em cada Estado, em cada região, conforme sua própria organização local: comitê, comissão, coletivo, coordenação, etc. Articulou-se um coletivo local que passou a acompanhar, coordenar e representar a região na coordenação dos três Estados, bem como em todas as atividades relativas à Universidade, que ainda não passava de um sonho possível, mas distante. 
A proposta pautava-se nas necessidades regionais de cada território - conjunto de municípios, todos carentes de oferta de ensino superior público e com grande depressão econômica e social - e nos programas recentes de desenvolvimento do ensino superior federal.

O Programa Universidade para Todos (ProUni), o Programa de Apoio a Planos de Reestruturação e Expansão das Universidades Federais (Reuni) e o Programa de Interiorização do Ensino Superior do MEC davam conta de que o momento era propício para propostas mais ousadas na busca por uma universidade de qualidade e ao alcance de todos, sobretudo daqueles públicos historicamente excluídos: os agricultores familiares e os camponeses. Municípios gaúchos não contemplados pelas extensões das universidades federais já existentes, pela criação da Universidade Federal do Pampa (Unipampa), pelas universidades comunitárias e estaduais nos demais Estados, fizeram com que dez regiões gaúchas, cinco catarinenses e duas paranaenses, totalizando mais de 400 municípios, iniciassem grandes movimentos por universidade pública federal.

Havia também a proposta do presidente Lula, quando de sua visita à Região Sul por ocasião da Caravana da Agricultura Familiar no inicio da década, da criação de uma universidade para o desenvolvimento dessas regiões.

Em uma das audiências realizadas em Brasília com o ministro da Educação, Fernando Haddad, é que foi lançado um dos grandes desafios, que dizia respeito exatamente à unificação do movimento: um Movimento só para os três Estados.

Deste encaminhamento estabeleceu-se uma meta de realização de seminários locais em preparação a um grande Seminário em Chapecó, SC.

No Território Cantuquiriguaçu, o Seminário aconteceu em Rio Bonito do Iguaçu, nos dias 18 e 19 de agosto de 2006, e elegeu um coletivo de representantes dos vários municípios e entidades comprometidos na construção da nova universidade. Este coletivo assumiu a tarefa não só de preparar e realizar os seminários, mas de promover a mobilização local necessária para que a ideia tomasse corpo e volume.

Nesses seminários foram definidas as diretrizes do movimento pró-universidade, sua coordenação, organização, objetivos estratégicos, formação, bem como o perfil da universidade buscada, tendo em vista uma grande crítica à universidade tradicional.

O Seminário Mesorregional aconteceu nos dias $1^{\circ}$ e 2 do mês de setembro de 2006 e teve como principais objetivos: a) Unificação do Movimento dos Três Estados do Sul com proposta única para o MEC; b) Definição do caráter, da missão, da coordenação e do papel político do movimento pró-universidade; c) Foco e estratégia de luta; d) Princípios da nova universidade que estava sendo reivindicada; e) Análise de exemplos de universidades populares.

Formaram-se duas coordenações interestaduais: uma pedagógica, cuja representação de nossa região ficou a cargo de Elemar do Nascimento Cezimbra, e outra política, em que a representação de nossa região e do Paraná ficou a cargo de João Costa de Oliveira. 
A coordenação pedagógica teve como missão o debate do caráter, dos princípios e fins da Universidade e a responsabilidade da elaboração do projeto de lei que, três anos mais tarde, criaria a UFFS. Esta importante tarefa foi dividida com o Grupo de Trabalho do próprio Ministério da Educação.

A coordenação política teve como tarefa, em primeiro lugar, convencer o ministro da Educação e sua equipe, bem como outros ministros afins, sobre a necessidade e a importância da criação da nova universidade, cuidar das estratégias de luta e promover a mobilização e a articulação necessárias para que o projeto de lei ficasse pronto, fosse enviado ao Congresso Nacional e, tão logo, fosse aprovado.

A coordenação geral do Movimento ficou a cargo da Via Campesina - formada por movimentos como MST, Movimento dos Atingidos por Barragem (MAB), MPA e Movimento de Mulheres Camponesas (MMC) e da Fetraf. A secretaria geral ficou estabelecida em Chapecó, SC, onde aconteceram os principais debates do movimento em nível mesorregional e as reuniões das coordenações política e pedagógica.

Com o Movimento unificado, a ideia de uma universidade federal multicampi ganhou grande impulso junto ao Governo Federal. Em 2007, o deputado federal por Santa Catarina Claudio Vignatti, assessorado por professores da Universidade Federal de Santa Maria, RS, apresentou um primeiro projeto de lei que criava a Universidade Federal para a Mesorregião Grande Fronteira do Mercado Comum do Sul (Mercosul) e seu entorno. Esse projeto já contava com alguns dos princípios norteadores da Universidade discutidos pelo movimento pró-universidade.

Os debates se seguiram, em forma de seminários, reuniões, palestras, mobilizações, passeatas, envolvendo os vários setores da sociedade, em diversos níveis. Nesses debates era feita a crítica à universidade convencional e tradicional, que normalmente reproduz o sistema de exclusão presente na sociedade atual, fortalece setores dominantes desta sociedade e nega acesso ao conhecimento e espaço às camadas mais empobrecidas. Em geral, as universidades atuais, públicas ou privadas, estão fechadas a determinados segmentos e só produzem em função de uma minoria elitizada.

A proposta dessa nova universidade balizava-se em uma compreensão democrática, humanizadora, encarnada na realidade local, comprometida com a justiça social e capaz de contribuir com os processos de desenvolvimento de cada local onde fosse instalada.

Assim, em 15 de setembro de 2009 criava-se a UFFS pela Lei n ${ }^{\circ}$ 12.029, abrangendo 396 municípios da Mesorregião Fronteira Mercosul: Sudoeste do Paraná, Oeste de Santa Catarina e Noroeste do Rio Grande do Sul.

\section{Construindo e organizando a universidade: os cursos e as estratégias de promoção de ações afirmativas}

Para os movimentos sociais e organizações implicados no processo de construção da Universidade, ficou explícita, desde o princípio, a necessidade de continuar no acompanhamento das ações e estratégias, 
compreendendo ser insuficiente limitar suas bandeiras de lutas na pura e simples reivindicação de instalação de um campus. Almejar uma instituição verdadeiramente comprometida com a inclusão, numa perspectiva transformadora, requer uma firme tomada de posição política em relação ao caráter democrático, público e popular. Entretanto, é preciso ter clareza de que esta tarefa nem sempre é simples, haja vista as contradições e disputas de interesses inerentes ao sistema social vigente.

Essas contradições aparecem em diversas experiências e são apontadas por Fleuri (2001) em estudo que trata da relação entre universidade e educação popular:

O esforço da classe dominante por controlar a universidade, contrariando as lutas populares pela democratização do ensino, atesta a importância dessa instituição como palco de lutas de classes.

Por um lado, o processo de privatização do ensino, imposto pela política educacional nestes últimos vinte anos, contribui para elitizar cada vez mais a universidade, restringindo-lhe o acesso a apenas uma parcela da classe média, facilmente cooptável pela burguesia. Mas a elitização da universidade decorre não só de seu restrito número de vagas: resulta sobretudo de seu caráter burocrático que determina a reprodução de um saber fragmentado e desvinculado da práxis social, facilitador da dominação e dificultador da transformação social.

Por outro lado, a luta popular pelo ensino público e gratuito não se limita à busca de ampliação do número de vagas. Ela visa a colocar todo o sistema de ensino, inclusive a universidade, a serviço da construção do poder popular. Neste sentido, a criação da universidade pública e popular implica necessariamente a reformulação de sua estrutura de poder e de seus processos de saber, consoante as lutas mais amplas da classe trabalhadora. Nesta perspectiva, a extensão universitária é pensada como uma estratégia para unir os processos de transformação estrutural da universidade aos da sociedade.

A partir do debate inicial realizado no movimento pró-universidade da região, fica evidente a adoção de uma postura política que permeará os diversos documentos norteadores da UFFS. Em seu Projeto Pedagógico Institucional (PPI) fica estabelecido que a Universidade deve estar "comprometida com o desenvolvimento sustentável e solidário da região" e que seus cursos deverão "privilegiar as vocações da economia regional, visando o desenvolvimento regional integrado, tendo na agricultura familiar um setor estruturador e dinamizador do processo de desenvolvimento" (UFFS, 2010b).

Além disso, outro ponto importante relativo aos cursos de graduação refere-se ao atendimento às diretrizes da Política Nacional de Formação de Professores do Ministério da Educação, "cujo principal objetivo é coordenar os esforços de todos os entes federados no sentido de assegurar a formação de docentes para a educação básica em número suficiente e com qualidade adequada" (Brasil. Decreto nº 6.755/2009).

Nesta perspectiva, foram criados 33 cursos no total, distribuídos em 42 turmas ingressantes anualmente.

No Rio Grande do Sul, o Campus Cerro Largo oferece atualmente os cursos de Agronomia com ênfase em Agroecologia, Desenvolvimento 
Rural e Gestão Agroindustrial, Engenharia Ambiental e Energias Renováveis, Licenciatura em Ciências - Biologia, Química e Física - e Licenciatura em Português e Espanhol. No Campus Erechim são contemplados os cursos de Arquitetura e Urbanismo, Agronomia com ênfase em Agroecologia, Engenharia Ambiental e Energias Renováveis, e os Cursos de Licenciatura em Pedagogia, Filosofia, Sociologia, História e Geografia.

Em Santa Catarina, no Campus Chapecó, onde também está instalada a reitoria da UFFS, são encontrados os cursos de Administração com ênfase em pequenos empreendimentos e cooperativismo, Agronomia com ênfase em Agroecologia, Engenharia Ambiental e Energias Renováveis, Ciência da Computação, Enfermagem e os Cursos de Licenciatura em Pedagogia, Português e Espanhol, Filosofia, Sociologia, História e Geografia.

No Paraná, o Campus Realeza oferece os cursos de Medicina Veterinária, Nutrição e Licenciatura em Português e Espanhol e de Licenciatura em Ciências: Biologia, Química e Física.

Também localizado no Estado do Paraná, o Campus Laranjeiras do Sul organizou cinco cursos voltados e preocupados com o desenvolvimento regional, abrangendo as ciências agrárias, a indústria, a gestão e o ensino voltado para a formação de professores do campo. São eles: Engenharia de Aquicultura, Engenharia de Alimentos, Agronomia com ênfase em Agroecologia, Desenvolvimento Rural e Gestão Agroindustrial e Licenciatura em Educação do Campo. Os profissionais formados pela instituição terão uma preocupação em desenvolver pesquisas e trabalhos que possam ser aplicados aos interesses dos habitantes da região.

Como critério de seleção de candidatos para os cursos de graduação estabeleceu-se o resultado do Exame Nacional do Ensino Médio (Enem), que é acrescido de um índice relacionado ao tempo de formação do candidato em escolas públicas. Esse índice, denominado Fator Escola Pública (FatorEP), é aplicado de acordo com a seguinte regra:

I) FatorEP $=1,3$ para o candidato que declarou ter cursado integralmente, com aprovação, todo o ensino médio em escola pública;

II) FatorEP $=1,2$ para o candidato que declarou ter cursado, com aprovação, apenas duas séries do ensino médio em escola pública;

III) FatorEP $=1,1$ para o candidato que declarou ter cursado, com aprovação, apenas uma série do ensino médio em escola pública;

IV) FatorEP $=1,0$ para os demais candidatos.

A Nota Final de cada candidato no Processo Seletivo é calculada utilizando-se a seguinte fórmula: Nota Final $=$ NotaEnemMédia $\times$ FatorEP. (UFFS. Edital no 162/UFFS/2011).

Esse mecanismo, como veremos posteriormente, é bastante significativo na popularização dos cursos oferecidos no Campus Laranjeiras do Sul.

Como estratégias organizacionais, a Universidade tem investido na criação de instâncias de decisões colegiadas e de abrangência comunitária, como é o caso do Conselho Estratégico Social, formado por membros representantes da comunidade externa, cujo objetivo, segundo a portaria de criação, é "assegurar a construção de uma instituição de educação 
superior comprometida com a inclusão social e com a produção e a disseminação do conhecimento para a melhoria da qualidade de vida das pessoas". Também se destaca a constituição do Conselho Universitário (Consuni), formado por representantes docentes, técnicos administrativos e discentes eleitos por seus pares a cada dois anos.

Outro espaço importante de discussão coletiva foi a realização da I Conferência de Ensino, Pesquisa e Extensão (Coepe), realizada durante os meses de junho a agosto de 2010, que teve como principais finalidades mobilizar a comunidade acadêmica para a definição das políticas norteadoras do ensino, da pesquisa e da extensão e aprofundar a interlocução com a comunidade regional, visando eleger as agendas prioritárias da UFFS nos campos da pesquisa e da extensão e as suas articulações com o ensino. Dessa conferência resultou um documento final cuja pretensão é subsidiar a política de extensão nos próximos anos.

Se observarmos este primeiro ano de existência, muitas ações estão sendo propostas no sentido de encontrar formas institucionalmente mais condizentes com uma concepção de participação; entretanto, estas aspirações, por vezes, esbarram na complexidade administrativa e organizacional que independem da vontade local, e em muitas situações percebem-se tomadas de decisões e atitudes que revelam posições hierarquizadas e centralizadoras.

Por outro lado, é preciso reconhecer que alguns avanços podem ser apontados; um exemplo a ser citado é o papel e a atuação dos colegiados de cursos.

Os colegiados são formados pelo coordenador do curso, pelos docentes que ministram componentes curriculares do curso no semestre letivo, pelos docentes do núcleo estruturante e por um representante do corpo discente, eleito anualmente entre os estudantes do curso.

Entre as várias atribuições do colegiado de curso está a de "estabelecer procedimentos para promover a integração e a interdisciplinaridade entre os componentes curriculares do curso, visando garantir sua qualidade didático-pedagógica" (inciso V, art. $3^{\circ}$ do Regimento).

Neste sentido, o colegiado de curso pode ser visto como um importante espaço de reflexões e avaliação dos processos pedagógicos vivenciados, principalmente nos primeiros anos de existência da Universidade, considerando um grupo relativamente pequeno de turmas e de professores componentes do colegiado. Desta forma, as discussões em torno da aprendizagem e acompanhamento dos estudantes têm tido expressiva relevância.

Como referência, podemos citar o caso do colegiado do curso de Licenciatura em Educação do Campo, que tem se tornado um espaço importante de avaliação sobre o desenvolvimento da aprendizagem dos acadêmicos.

Em levantamento realizado com os professores que atuaram na primeira turma desta licenciatura, foram detectados níveis expressivos de dificuldades pela maioria dos estudantes. De acordo com os nove professores que participaram do questionário, identificou-se que a dificuldade 
mais aparente reflete-se na habilidade da escrita, relacionada à elaboração e argumentação em questões dissertativas, bem como nas questões estruturais. Também foram apontadas como limitantes as dificuldades em relação à apropriação de conceitos básicos e habilidades de leitura relativas a interpretação, capacidade de análise e síntese de textos.

Esta situação pode ser atrelada à condição de que existem defasagens concretas relativas aos conteúdos desenvolvidos no ensino médio. Pensando nisso, optou-se, no próprio Projeto Institucional da UFFS, pelo desenho de um currículo composto por três eixos: o Domínio Comum, o Domínio Conexo e o Domínio Específico.

As disciplinas do Domínio Comum possuem justamente a intencionalidade de solidificar uma base necessária que garanta aperfeiçoamento e qualificação posterior. Estas disciplinas possuem como principais objetivos:

a) desenvolver em todos os estudantes da UFFS as habilidades e competências instrumentais consideradas fundamentais para o bom desempenho de qualquer profissional (capacidade de análise, síntese, interpretação de gráficos, tabelas, estatísticas; capacidade de se expressar com clareza; dominar minimamente as tecnologias contemporâneas de informação e comunicação); e

b) despertar nos estudantes a consciência sobre as questões que dizem respeito ao convívio humano em sociedade, às relações de poder, às valorações sociais, à organização sócio-político-econômica e cultural das sociedades, nas suas várias dimensões (municipal, estadual, nacional, regional, internacional). (UFFS, 2010b).

Outra dificuldade apresentada no levantamento refere-se às práticas de estudo; ou seja, segundo a opinião dos professores, identificou-se que, de forma geral, os estudantes da turma apresentaram relativa dificuldade em realizar atividades fora do horário escolar, na revisão de conteúdos, no estudo para provas e na resolução de exercícios e tarefas.

Por outro lado, o desempenho dos estudantes foi considerado melhor no que se refere ao acompanhamento em sala, na demonstração de compreensão das explicações, na expressão oral, na participação em debates e na fluência das intervenções e perguntas durante as aulas.

Quando perguntados sobre os motivos considerados significativos para a incidência destas dificuldades, os professores apontaram como principal fator a "ausência da cultura universitária e desconhecimento de técnicas e práticas de estudo"; o segundo motivo apresentado associa estas defasagens ao fato de que "os estudantes são em sua maioria provenientes de um ensino médio deficitário"; e a terceira causa apontada retrata "a falta de disciplina, interesse e motivação por parte dos acadêmicos".

A mesma questão também foi apresentada aos acadêmicos do Curso de Licenciatura em Educação do Campo, para que apontassem as razões que podem ter ocasionado dificuldades de aprendizagem. O primeiro motivo citado sugere que "o estudante deparou-se com conteúdos difíceis, acima de sua compreensão"; como segundo fator constatou-se "a falta de conhecimentos prévios que deveriam ter sido apropriados no ensino médio"; a terceira razão remete "ao volume excessivo de conteúdos 
e leituras a serem executadas"; e o quarto motivo apresentado pelos estudantes foi "a falta de tempo e de hábito de estudo em casa".

É pertinente ressaltar que esse levantamento não teve a pretensão de justificar as defasagens apresentadas pelos alunos, mas reforça a ideia de que, a partir da situação detectada, torna-se fundamental promover ações que possam dar suporte material para sanar essas dificuldades. Neste sentido, analisando os motivos apresentados tanto pelos professores como pelos estudantes, podemos afirmar que é necessário promover uma ampliação do tempo dedicado aos estudos, sendo uma das ferramentas utilizadas a concessão de bolsas de estudos.

No primeiro ano de funcionamento da UFFS houve a destinação de bolsas com a intencionalidade de contribuir com o processo de acesso e permanência de estudantes em situação de vulnerabilidade social. Essas bolsas foram organizadas em duas modalidades: "Bolsas de Iniciação Acadêmica", para que os estudantes cumpram 20 horas semanais de atividade com a orientação de um professor orientador, e "Bolsa Permanência", para que o acadêmico selecionado precise manter frequência e rendimento acadêmico satisfatórios.

No ano de 2011 a Universidade também ofereceu auxílios com o objetivo de complementar as despesas do estudante com moradia, alimentação ou transporte, uma vez que, anteriormente ao seu ingresso, ele não possuía tais gastos.

E a partir de uma demanda crescente em relação às defasagens de aprendizagem, será proposta uma nova modalidade de bolsa: a Bolsa de Estudos Orientados, que, de acordo com o Edital No 045/UFFS/2011, tem como objetivo "Propiciar ao estudante de graduação em situação de vulnerabilidade socioeconômica, a partir de sua inserção em grupos de estudos em sua área de formação e da concessão de bolsas, condições mais igualitárias para que ele possa responder às demandas de uma formação universitária" (UFFS, 2011).

\section{Perfil dos acadêmicos da UFFS - Laranjeiras do Sul}

O campus de Laranjeiras do Sul iniciou-se com a criação de cinco cursos: Engenharia de Aquicultura, Agronomia com ênfase em Agroecologia, Desenvolvimento Rural e Gestão Agroindustrial, Engenharia de Alimentos e Licenciatura em Educação do Campo. O início das atividades acadêmicas (I semestre de 2010) contou com 212 estudantes, distribuídos nos cinco cursos da Universidade. No II semestre de 2010, o número de estudantes aumentou para 270 e, atualmente (I semestre de 2011), chega a aproximadamente 400 estudantes. A previsão é de que no final do ano o número de acadêmicos cresça para mais de 1.000 .

Nesse sentido, podemos afirmar que a UFFS interfere radicalmente na dinâmica das regiões em que se insere, seja do ponto de vista objetivo, seja do ponto de vista subjetivo. 
Do ponto de vista objetivo, verificamos mudanças concretas em relação às questões econômicas. Presente em uma cidade com pouco mais de 30.000 habitantes e com graves problemas no que diz respeito ao desenvolvimento humano, conforme apontado anteriormente, a UFFS disponibiliza somente em bolsas de iniciação e de permanência acadêmica $\mathrm{R} \$ 36.000$ por mês para estudantes da região. ${ }^{1}$ Presume-se que esse dinheiro seja gasto na própria cidade e, assim, acabe movimentando o comércio e outras atividades produtivas.

Do ponto de vista subjetivo, fica claro que a Universidade muda o cenário artístico, intelectual, político e social. A troca de experiências com professores das mais diversas áreas do conhecimento proporciona o exercício constante de crítica, seja das ações individuais ou coletivas. Além disso, eleva-se a autoestima de acadêmicos e famílias, pois muitos deles são as primeiras pessoas da família a entrar no ensino superior.

De qualquer forma, o perfil diferenciado dos acadêmicos coloca em evidência "novos" e "velhos" problemas, especialmente em relação ao desempenho dos estudantes. Sabemos que os déficits da educação básica não estão restritos ao nível público: escolas particulares, extremamente competitivas nos mais variados sistemas seletivos, deixam lacunas enormes na formação dos seus estudantes, especialmente em relação às contribuições no campo político e social.

Para efeito das análises posteriores, utilizaremos dados das fichas de matrículas dos discentes que entraram no I semestre de 2010 na Universidade Federal da Fronteira Sul (Campus Laranjeiras do Sul/PR). Ao todo foram tabuladas e analisadas 168 fichas de matrículas de um total de 212 estudantes (I semestre). Os acadêmicos responderam a diversas questões, sendo que as mais importantes para a realização deste trabalho são analisadas no decorrer do texto. Em outros gráficos realizamos uma comparação com o perfil discente da Universidade Estadual de São Paulo (USP), com base em pesquisa Datafolha realizada em 2005, intitulada "Perfil dos alunos aprovados no vestibular da USP, 2005". ${ }^{2}$

${ }^{1}$ Atualmente contamos com mais de 40 professores e 30 funcionários na UFFS Laranjeiras do Sul/ PR. Se levarmos em conta que em muitas cidades do Brasil a principal fonte de renda são os recursos vindos de transferências governamentais, Laranjeiras do Sul sofre uma interferência radical nas relações econômicas e sociais, demandando mais serviços, atividades culturais, etc.

${ }^{2}$ A base de dados está disponível no Consórcio de Informações Sociais < http://www.nadd.prp. usp.br/cis/index.aspx $>$.

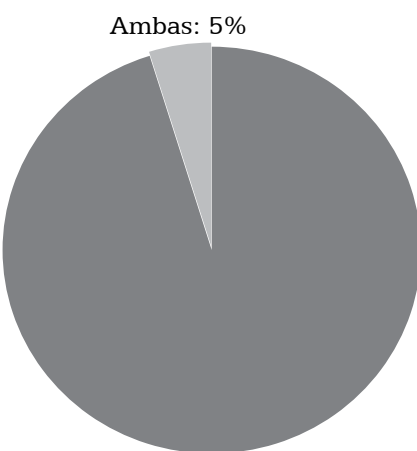

\section{Gráfico 1 - Origem do Ensino Fundamental e Médio - Escola Pública ou} Particular

Fonte: Fichas de matrículas da UFFS Laranjeiras do Sul (PR)
Apenas escola pública: 95\% 
Na UFFS Laranjeiras do Sul-PR, 95\% dos estudantes realizaram sua formação básica (ensino fundamental e médio) em escola pública, e o restante (5\%), em escola particular e pública. Para efeito de comparação, vemos que o percentual de estudantes que entraram na USP tendo realizado sua formação básica apenas em escola pública foi de 13\%; os outros $87 \%$ a obtiveram em escola particular. Constatamos então que, no que diz respeito ao campo social e da afirmação das minorias, a instituição contribui para a correção de um grande problema presente em todo o território nacional: a baixa presença de estudantes oriundos do ensino público nas universidades estaduais e federais.

O ponto positivo situa-se no fato de que esses estudantes jamais poderiam cursar uma instituição de ensino superior, seja de caráter privado ou público. As universidades particulares não seriam acessíveis por conta dos altos custos das mensalidades. Dos estudantes pesquisados, 55\% situam-se em famílias com renda mensal entre 1 e 3 salários mínimos, apenas 5\% vivem em famílias com renda mensal maior que 5 salários mínimos. Ao compararmos com a USP, por exemplo, veremos que disparidade é enorme: 79\% das famílias dos seus estudantes possuem renda familiar acima dos 5 salários mínimos.

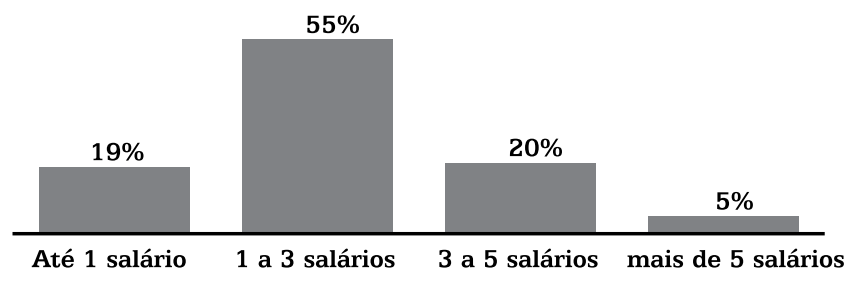

Gráfico 2 - Renda Familiar Mensal

Fonte: Fichas de matrículas UFFS Laranjeiras do Sul (PR)

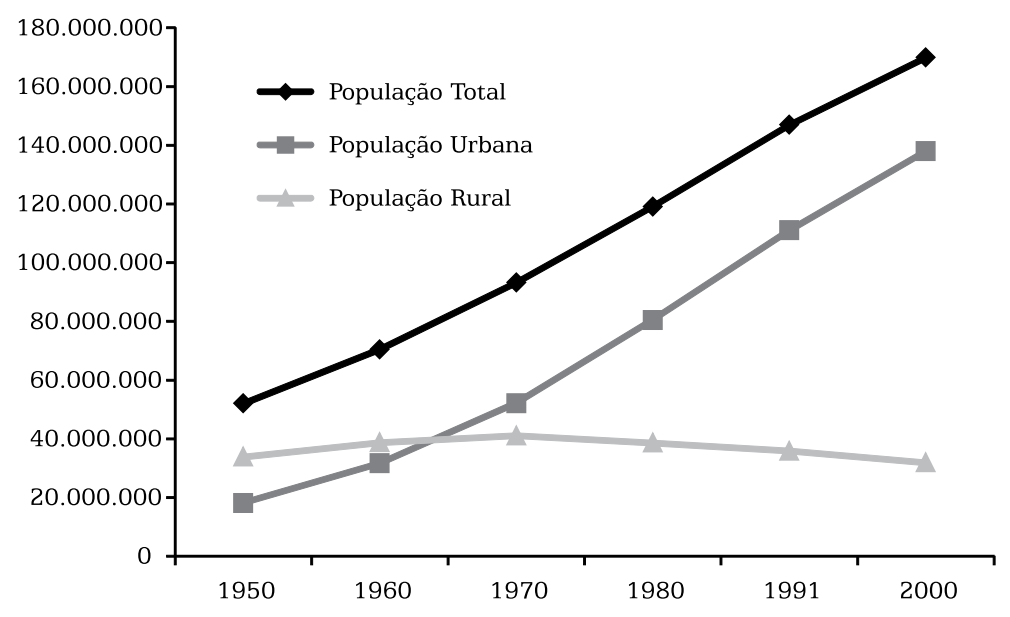

Gráfico 3 - Censo Demográfico 2000 - Migração e Deslocamento no Brasil

Fonte: Instituto Brasileiro de Geografia e Estatística (IBGE) - Censo 2000. 
Além disso, sabemos que as capitais e as grandes cidades do Brasil sempre foram privilegiadas como sede das universidades federais, provocando, dessa maneira, uma litoralização do ensino. Essa disposição territorial contribuiu para a exclusão da maioria dos jovens do ensino superior, especialmente aqueles que vivem em regiões mais afastadas do litoral e dos grandes municípios. Em resumo, além da exclusão de renda, verificamos uma exclusão simbólica e territorial. Isso é mais evidente no Território da Cidadania Cantuquiriguaçu, por se tratar de uma região voltada para a agricultura. O processo de industrialização pelo qual o Brasil passou, principalmente na metade do século 20, acarretou um aumento considerável da população urbana, removendo enormes contingentes de pessoas do campo para a cidade.

Os grandes fluxos de migração do passado continuam até hoje. É bastante comum o fato de os jovens deixarem o campo em busca de melhores condições de vida nos centros urbanos; fatores como o baixo acesso ao ensino superior contribuem para esse fenômeno. Sem uma instrução adequada - tanto no sentido de proporcionar a formação e melhorar sua condição de vida quanto no sentido de possibilitar o desenvolvimento regional -, esses jovens obrigam-se a deixar suas cidades de origem. Nesse sentido, a mulher e o homem do campo são excluídos de forma sistemática do ensino superior. A UFFS fixa-se numa região predominantemente agrícola, e isso se reflete no perfil dos seus estudantes. Quando analisamos a profissão dos pais, podemos verificar que mais da metade (57\%) são agricultores; esse número também é elevado entre as mães: $37 \%$ são agricultoras, porém a profissão de dona de casa aparece com $24 \%$. Chama a atenção o fato de que boa parte das profissões não demandam ensino superior, revelando o grau de vulnerabilidade familiar. A UFFS torna disponível o ensino superior para filhos de agricultores, sem o que, em época recente, eles contribuiriam para a elevação do número de pobres nas grandes cidades.

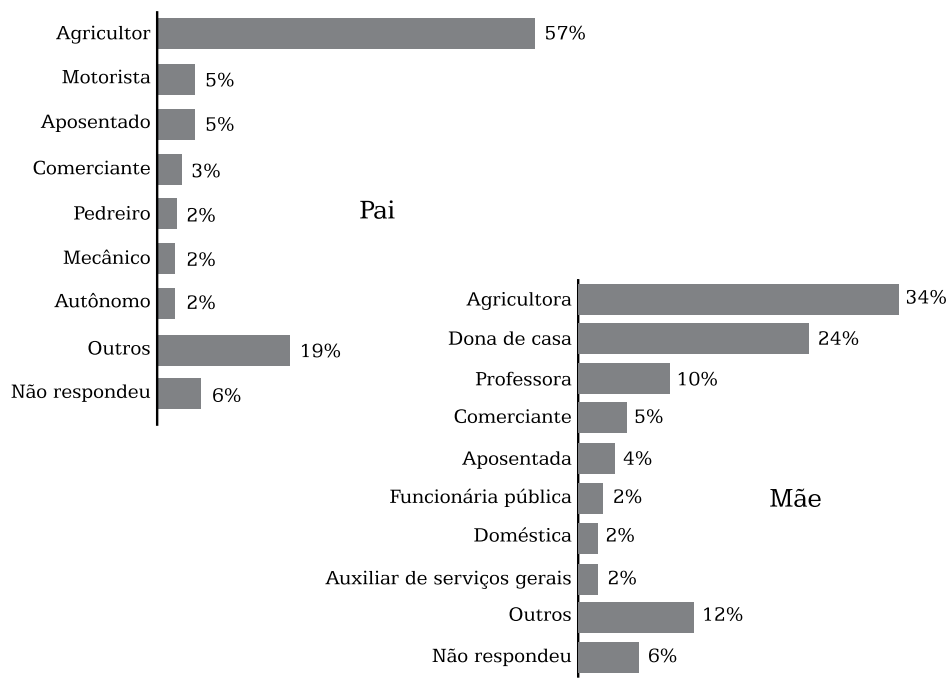

Gráfico 4 - Profissão do Pai e da Mãe

Fonte: Fichas de matrículas da UFFS Laranjeiras do Sul (PR) 
O processo de inclusão da UFFS também se dá nos níveis regional e geracional: 86\% dos estudantes são do próprio Estado do Paraná, 46\% destes, de Laranjeiras do Sul - cidade que possui campus da UFFS - e os restantes estão distribuídos nas cidades vizinhas. A Universidade possibilita o ensino para jovens que não poderiam se deslocar até os grandes centros, porém não só os jovens a frequentam: há um elevado número de estudantes com idade superior aos 20 anos, fato incomum nas universidades federais e estaduais. Na USP, por exemplo, dos estudantes aprovados no processo seletivo de 2005, 75\% encontravam-se na faixa etária dos 18 aos 24 anos, enquanto que na UFFS esse percentual se reduzia para $52 \%$.

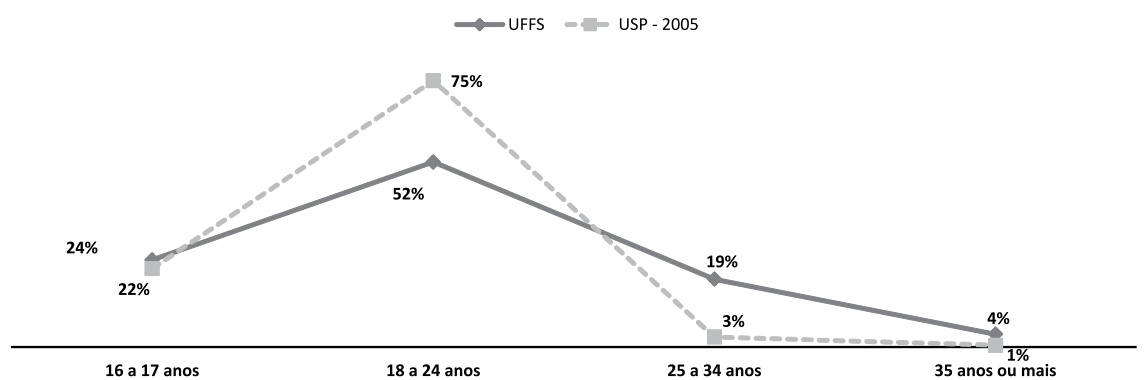

Gráfico 5 - Idade dos Acadêmicos (UFFS e USP)

Fontes: 1) Fichas de matrículas da UFFS Laranjeiras do Sul (PR)

2) Datafolha: Perfil dos alunos aprovados no vestibular da USP, 2005

A UFFS potencializa-se como uma experiência positiva para a redução das desigualdades locais. O processo de inclusão social se dá entre os jovens filhos de agricultores e entre as pessoas que não puderam estudar quando finalizaram seu ensino médio. Basta analisarmos o Gráfico 6, a seguir: dos estudantes que entraram na UFFS no I semestre de 2010, 76\% finalizaram o ensino médio entre 2005 e 2009, e, desse total, apenas 13\% em 2008 e 46\% em 2009.

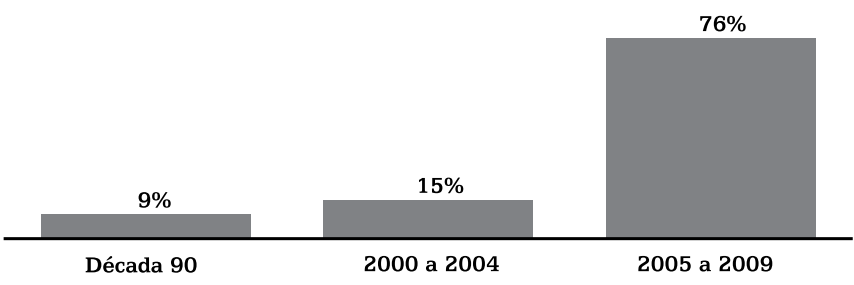

Gráfico 6 - Ano de Conclusão do Ensino Médio

Fonte: Fichas de matrículas da UFFS Laranjeiras do Sul (PR)

Além da inclusão geracional, a UFFS contribui para a inclusão regional, de renda e, também, de gênero: $61 \%$ dos estudantes são do sexo feminino. Em nossa atividade diária no campus, identificamos diversas estudantes mulheres com idade superior a 25 anos, casadas e mães. Com 
frequência, elas relatam que deixaram de entrar na universidade devido à impossibilidade de conciliar as atividades familiares com os estudos, e, agora, pelo fato de a universidade se localizar em sua região, podem concretizar o sonho do ensino superior.

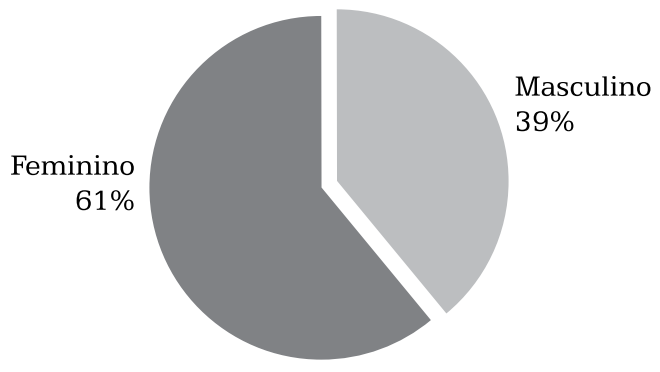

Gráfico 7 - Sexo dos Estudantes

Fonte: Fichas de matrículas da UFFS Laranjeiras do Sul (PR)

Em síntese, a Universidade consolida-se como um espaço público garantidor da inclusão de minorias historicamente excluídas do desenvolvimento econômico, social e político, entretanto, mesmo com todas essas experiências positivas, constatamos que ela não abrange por completo os grupos sociais discriminados: para negros e índios o ensino superior parece distante.

${ }^{3}$ Utilizamos os termos "cor e raça" e as classificações "branCO", "preto", "pardo", "amarelo" e "indígena" por levarmos em consideração a categorização realizada pelo Instituto Brasileiro de Geografia e Estatística (IBGE). Entendemos que o debate étnico não pode ser reduzido as essas cinco classificações; os movimentos negros, por exemplo, chamam a atenção para a necessidade de assumir sua identidade de negros, removendo os termos pardos, morenos, etc. A construção étnica não é apenas uma relação de cor ou raça, mas volta-se para a dimensão do ser humano, sua vida coletiva e práticas culturais.

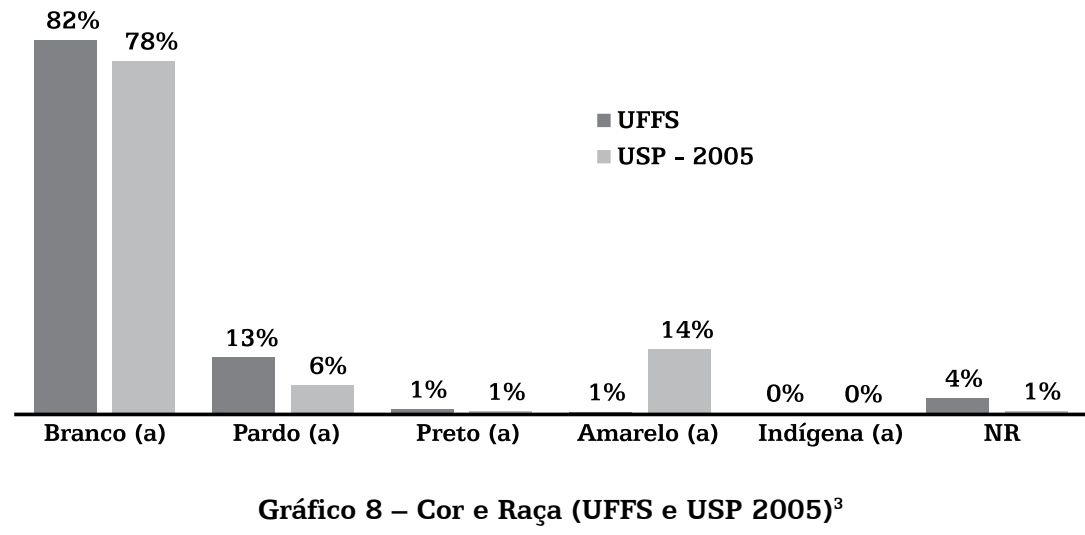

Fontes: 1) Fichas de matrículas da UFFS Laranjeiras do Sul (PR)

2) Datafolha: Perfil dos alunos aprovados no vestibular da USP, 2005

A UFFS garante o acesso a pessoas mais velhas, mulheres, filhos de agricultores, etc., mas ainda não consegue incluir negros e índios. Isso fica evidente e preocupante se levarmos em conta que no território da Cantuquiriguaçu existe a maior comunidade indígena do Paraná - a Comunidade Rio das Cobras - e diversas de origem quilombola. De todos os dados que analisamos, é o único que se parece com o perfil dos estudantes da USP. Dos estudantes que declararam sua cor/raça na UFFS e 
na USP, apenas 1\% se identificaram como "preto". A gravidade se amplia para os indígenas: as duas universidades juntas não chegam a somar 1\%. O processo de inclusão não acontece por completo, as questões étnicas se consolidam como um grande tabu, e a "democracia racial brasileira" reivindicada por muitos e orgulho de tantos não acontece na prática. A população negra comparada à branca ainda possui os piores salários, a menor renda e é constantemente vítima de homicídios. Se é sinônimo de emancipação humana, a educação se restringe a uma pequena parte da população.

Por se tratar de um local que em determinado período histórico recebeu um contingente elevado de migrantes europeus, convencionou-se acreditar que esse era o único povo pertencente a Laranjeiras do Sul. A dinâmica da distribuição étnica é muito mais complexa. A região é formada por pequenos agricultores, indígenas, descendentes europeus, negros, etc. A pobreza existente nos indicadores transforma-se em riqueza quando a questão é a sua diversidade e pluralidade cultural. O noroeste do Paraná apresenta o maior percentual de "pretos" e "pardos", mas se traçamos uma linha divisória entre norte e sul, identificamos três polos de concentração da população "preta" e "parda", e um deles é circunscrito pelo município de Laranjeiras do Sul. Se o cidadão laranjeirense está na periferia do Estado, a população negra e indígena encontra-se na periferia da periferia.

Portanto, para a UFFS se consagrar como uma experiência popular e democrática, a instituição deve realizar um acompanhamento social, cultural e político das temáticas anteriores. A análise das desigualdades e a promoção da educação para as minorias devem ser políticas periódicas. Porém não basta simplesmente dar o espaço para esses grupos historicamente excluídos; é imprescindível que o acesso à universidade seja acompanhado por políticas de permanência, claras e eficientes, que permitam aos discentes o exercício pleno da educação superior, participando ativamente do ensino, da pesquisa e da extensão. O desafio da qualidade também deve ser encarado. Por se tratar de um perfil diferenciado de estudantes, muitos deles entram na universidade com enormes lacunas oriundas de sua formação básica. As universidades que buscam se afirmar como instituições diferenciadas não podem exercer um preconceito às avessas, constrangendo esse "novo" público universitário. Os professores e toda a comunidade universitária devem assumir o compromisso da educação como emancipação humana. Se vivemos em "tempos sombrios", como coloca, Hannah Arendt nos dá o caminho para a mudança: a valorização plena dos espaços públicos e das pessoas.

\section{Da análise material do processo de acesso na UFFS como política afirmativa ao adentramento e questionamento no "território imaterial" das "formas" de acesso nas universidades públicas do Brasil}

Um balanço acerca da escola e da educação pública no início deste século, nos diferentes níveis, nos mostra um retrato constrangedor de uma dívida histórica, qualitativa e quantitativamente. 
Considerando o caminho analítico feito por este texto e de acordo com a materialidade analisada, verifica-se que a forma adotada para ingresso dos(as) acadêmicos(as) na UFFS se torna referência se considerado o princípio fundamental de que educação pública é direito de todos e dever do Estado,

Nesse sentido, este item tem a intencionalidade de discutir a linha tênue entre o "avanço" e os "limites" na implementação dessa política, levando em consideração que toda política nova que se apresenta como uma possibilidade contra-hegemônica pode contribuir com o alargamento das linhas limítrofes do já estabelecido.

A busca de implementar uma política que acolha a maioria dos sujeitos oriundos da educação pública traz à tona a necessária revisão das formas estabelecidas como política de acesso, ou pelo menos coloca em questão as políticas até então adotadas, que se apresentavam como "imutáveis", calcadas num discurso do direito igual a todos. Isso remete à discussão feita por Ciavatta, Frigotto e Ramos (2005, p. 7):

Há na sociedade brasileira um tecido estrutural profundamente opaco nas relações de poder e de propriedade que se move em conjunturas muito específicas, mas que, no seu núcleo duro, de marca excludente, de subalternidade e de violência, se mantém recalcitrante [...].

O essencial é apanhar as contradições, porque nelas torna-se possível buscar as positividades desse processo analisado, tendo em vista que os limites e as negatividades já estão dados e definidos, em grande parte, pela própria estruturação da sociedade e das políticas de educação no Brasil. Desse modo, as transformações que emergem das contradições, mesmo dentro de um sistema construído a partir da lógica estrutural capitalista, se materializam em espaços de transformação; mesmo que sejam minúsculos e vigiados, demonstram possibilidades de uma outra realidade possível. Afirma Gadotti (1995, p. 77):

Se amanhã uma educação transformadora for possível é apenas porque, hoje, no interior de uma educação conservadora, os elementos de uma nova educação, de uma outra educação, libertadora, formam-se dentro dessa educação. Essa mudança de espaço dominado para um espaço dominante não se fará nem espontaneamente nem de um momento para o outro $[\ldots]$.

A forma de acesso adotada pela maioria das universidades estaduais e federais não requer pensar uma política de permanência, tendo em vista que o processo instituído já faz a seleção necessária, pré-determinando pela "peneira" do vestibular o público que estará ocupando as vagas nelas existentes. De modo geral, a maioria dos(as) acadêmicos(as) que entravam/entram nas federais pelo critério meritocrático da nota do vestibular tinham e têm condições financeiras para se manter em seus cursos. Por outro lado, numa proposta de ampliação do acesso das camadas populares à universidade, deve vir junto, necessariamente, a ampliação das políticas de permanência. 
Essa política de acesso nasce a partir das discussões entre a comissão de implantação e o movimento pró-universidade, nasce, portanto, de uma materialidade bem definida, de um contexto histórico-social que manifesta um movimento dialético entre as formas dadas de políticas de ingresso e as proposições que vinham corresponder às necessidades amplamente debatidas a partir de uma região, visando um projeto institucional com objetivos claros de inclusão. De acordo com Lima Filho (2009, p. 2), ao discutir sobre o necessário controle social da universidade e sua na natureza,

\begin{abstract}
A UFFS obriga-se a ser uma instituição científica pública a oferecer ensino gratuíto e de qualidade, com caráter popular e democrático a serviço das maiorias trabalhadoras (através de suas devidas representações profissional, políticas, etc.), à solução dos emergentes e candentes problemas históricos regionais (de caráter socioeconômico e cultural) através de uma produção e reprodução do saber destinada, em consonância com as suas dimensões humanas mundiais, à emancipação humana.

O controle social seria desse modo o processo sistemático e orgânico e as suas formas de realização específica da produção e reprodução do saber com fins emancipadores explícitos centrados na transformação regional e através da ampliação do controle dos trabalhadores sobre os processos decisórios da UFFS.
\end{abstract}

Como já foi destacado, mais de 90\% dos acadêmicos da UFFS são oriundos da escola pública; se essa escola, em sua grande maioria, apresenta dificuldades na socialização e na produção do conhecimento científico, esse reflexo vem para a universidade. Notadamente, essa questão se torna matriz de constante debate na UFFS, uma vez que estamos navegando contra a corrente, ou seja, estamos atuando em um cenário novo que entrelaça o papel de uma universidade que acolhe filhos de trabalhadores e de professores que transitaram por um processo de formação que se efetivou em um modelo anterior, diferente.

Externadas algumas razões que justificam a necessidade dessa reflexão, retomamos o ponto central do debate destacando que esse processo traz as diferentes dimensões de uma instituição de ensino superior em construção, que perpassa os aspectos de gestão, elaboração dos Projetos Pedagógicos dos Cursos (PPCs) e da própria ação pedagógica cotidiana com os sujeitos educativos, ${ }^{4}$ levando em consideração o resultado de múltiplos fatores e diferentes determinações e observando os limites e as possibilidades de como a realidade se impõe.

Aspecto importante a ser destacado é o processo construído nesse período de discussão. O resultado desse processo demonstra que a proposição oriunda das organizações sociais e dos movimentos sociais, por estar calcada em uma realidade material normalmente de defasagem e falta de políticas verdadeiramente democráticas, faz com que a prática "costumeira" seja (re)pensada. A participação popular nas provocações de políticas públicas traz consigo determinadas características que é expressão de necessidades do que está historicamente posto à margem, pois a participação de organizações e de movimentos sociais possibilita o aparecimento de circunstâncias que, na maioria das vezes, não fazem
${ }^{4}$ Entende-se por sujeitos educativos todos os pares da comunidade acadêmica, professores(as), acadêmicos(as), pessoal técnicoadministrativo e comunidade externa. 
parte da estrutura hegemônica e universalista da concepção das políticas públicas estatais. Grande parte dos avanços protagonizados pela classe trabalhadora nas diferentes relações sociais, no mundo do trabalho e no acesso à educação não resulta mecanicamente da simples existência de contradições na materialidade social e, de igual forma, nem sempre são apenas brechas deixadas pela classe social que hegemoniza seus valores e é ocupada pela classe trabalhadora. É resultado, sobretudo, da compreensão e da apreensão da natureza dessas contradições, de uma discussão política madura e, em síntese, da organização da classe trabalhadora na luta por seus interesses.

Nesse sentido, em que pese o desafio que se apresenta a partir dessa política que visa à ampliação do acesso das camadas populares na universidade, há a construção e a pavimentação de uma via de mão dupla: de um lado, as dificuldades de achar meios, formas e estratégias para o enfrentamento das defasagens dos(as) acadêmicos(as) e, de outro, a necessidade de também a universidade pensar estratégias para contribuir com a educação básica nas escolas públicas.

Mas, de tudo isso, é perceptível que dois caminhos se insinuam: o caminho da acolhida dos modos convencionais de explicar a materialidade acima descrita ou o da possibilidade que é a proposição da ruptura. Como são contraditórios em processo, percebe-se ambas as saídas insuficientes para explicar esse cotidiano complexo que precisa ser analisado em sua amplitude, demonstrando a nossa limitação analítica a tempos densos imposta pela realidade com a qual nos defrontamos e a forma que tem um núcleo duro fortemente incentivador de nos aliarmos a modelos explicativos e de resoluções que subestimam o caráter contraditório do movimento da realidade que agora ocupa o espaço-tempo da universidade.

Outro aspecto relevante a ser debatido levando em consideração a política de acesso da UFFS é que esta se impõe como uma alternativa de democratização da educação pública superior. Nesse sentido, a implementação desse processo atinge e provoca o repensar de várias dimensões, tais como social, política, econômica, além de tensionar a concepção de políticas públicas em diferentes escolaridades.

Como uma proposta nova de política de acesso, há a ligação entre as diferentes dimensões de uma política educacional que se inscreve como uma alternativa de inclusão e a possibilidade de tensionar, articular, relacional e dialeticamente, a particularidade com a totalidade, bem como a relação entre concepção e a implementação/execução dessa política. "A UFFS, embora determinada pelos marcos institucionais federais, poderá ousar a vir a ser vanguarda experimental de uma educação descolonizada e emancipatória" (Lima Filho, 2009, p. 4).

Os aspectos que fazem essa necessária ligação compõem multiescalaridades que se relacionam constantemente, uma vez que essa política de acesso aparece por certa intensificação do debate gestado no movimento pró-universidade, portanto fruto da participação popular, dos sujeitos que compõem coletivos sociais que vivenciam a ausência de políticas públicas, e deste cenário há o tensionamento e a interlocução oficial com sujeitos 
gestores das políticas públicas que têm a responsabilidade de colocar no/ para o sistema uma forma concebida e construída pela base popular, bem como de dar respostas práticas às exigências, às reivindicações dessa base.

Nesse aspecto, acontece a relação dialética entre a particularidade e a totalidade, onde a proposição gestada nesta particularidade que adentra ao sistema educacional, além de questionar as práticas usuais entre as universidades, possibilita que esse processo hegemônico também possa olhar para essa experiência repensando conceitos cristalizados e discursos pedagogicamente corretos que mascaram a realidade e suas contradições reais nos processos de seleção daqueles que ocuparam e ocuparão as vagas nas universidades públicas do Brasil.

\section{Aspectos gerais de uma (in)conclusão necessária: necessários debates}

As mudanças provocadas, sobretudo, pela ação dos movimentos sociais do campo, embora fundamentais para o grande passo que foi a conquista da universidade federal para a região, não serão suficientes por si sós para tirar a região do atraso a que está submetida historicamente. Isto mostra que temos muitos e sérios desafios. As contradições inerentes na própria constituição da UFFS, onde se desenvolvem as possibilidades de ampliar o debate, são importantes para fomentar a implementação das políticas públicas formuladas desde a realidade, dos embates de projetos de desenvolvimento e o papel da universidade nesse processo.

Não há como avançar no rumo do desenvolvimento sem melhorar a capacidade de produção, sem desenvolver a contento as forças produtivas, sem avançar na cooperação para efetivamente socializar os lucros da produção, sem diminuir o tempo de trabalho bruto para o trabalhador rural a partir da pesquisa e da automação de processos produtivos e sem a evolução necessária no processo de humanização das relações a partir da educação humana e não apenas técnica.

Muitos limites e potencialidades já estão mapeados no Plano Diretor para o Desenvolvimento do Território Cantuquiriguaçu, mas têm, sobremaneira, desafiado nossa capacidade, exatamente pela ausência de uma instituição forte para a formação de profissionais nas várias áreas e dimensões.

Isto tudo somente será possível se a UFFS e as demais instituições de ensino superior, médio e fundamental cumprirem com sua função de produzir, disseminar e repensar o conhecimento e as práticas da sociedade local em todas as áreas, podendo contribuir com a superação das contradições sociais, políticas e econômicas do território, na mesma medida em que for capaz de superar também suas próprias contradições internas, próprias do modelo universitário vigente.

Conforme já amplamente discutido,

A universidade é uma instituição social que exprime e reflete, de modo historicamente determinado, a sociedade em que está inserida. Ela 
configura e dá forma às relações sociais, mas também é configurada por elas, pelos embates políticos e pelas disputas acadêmicas que atravessam e determinam o lugar social em que existe. Portanto, a sociedade brasileira em geral e a universidade em particular ainda carregam as marcas do colonialismo escravista, da cultura senhorial do patrimônio e das suas relações clientelistas e de favor. Dessa forma nossas universidades são predominantemente marcadas pelo domínio do mundo privado sobre o mundo público, do interesse particular sobre o coletivo, da hierarquia familiar sobre a ordenação cidadã, da amizade sobre o bem comum. (Duarte, Rampinelli, 2005, p. 30).

Por isso a importância de "cultivar", de estar permanentemente atento em relação aos processos internos e externos a serem instituídos. Essa forma de pensar o papel da UFFS pode fortalecer os mecanismos e meios de tornar públicos o conhecimento científico e a produção da tecnologia que darão de fato retornos práticos para o mundo do trabalho dos sujeitos dessa região.

É claro que a universidade não pode ser considerada o único vetor de desenvolvimento, mas, no caso desta região, é imprescindível, para que ocorram avanços na produção econômica, na produção de conhecimento, na produção e distribuição de justiça social. Para a consecução desses objetivos, é relevante considerar a necessidade de continuar com a mobilização e a organização social necessárias, aprimorando o processo, corrigindo erros e mantendo a luta como princípio orientador da ação coletiva.

Na esfera pedagógica, além de garantir o caminho do acesso, é preciso tensionar continuamente para que de fato as mudanças ocorram, respeitando a particularidade, mas sem negligência e defasagem na socialização do conhecimento, função primeira das instituições educacionais públicas.

A conquista da UFFS ainda não está completa e nem ficará completa um dia. A universidade é um campo de eterna disputa, porque envolve interesses, sobretudo econômicos. Embora não lhe caiba o papel de compensação social, poderá contribuir enormemente para com os processos de geração e distribuição de renda, na medida em que suas pesquisas estejam direcionadas à melhoria das condições de vida e trabalho da maioria da população. Arrisca-se a afirmar que um passo deste extenso caminho está sendo dado ao se produzir meios efetivos de acesso àqueles que historicamente estavam alheios a um local de privilégio.

\section{Referências bibliográficas}

ARENDT, Hannah. Homens em tempos sombrios. Lisboa: Relógio D'Água, 1991.

BRASIL. Decreto $n^{\circ}$ 6.755, de 29 de janeiro de 2009. Institui a Política Nacional de Formação de Profissionais do Magistério da Educação Básica, disciplina a atuação da Coordenação de Aperfeiçoamento de Pessoal de Nível Superior - CAPES no fomento a programas de 
formação inicial e continuada, e dá outras providências. Disponível em: < http://www.planalto.gov.br/ccivil_03/_ato2007-2010/2009/Decreto/ D6755.htm>.

CIAVATTA, Maria; FRIGOTTO, Gaudêncio; RAMOS, Marise (Orgs.). Ensino médio integrado: concepções e contradições. São Paulo: Cortez, 2005.

\section{CONSELHO DE DESENVOLVIMENTO DO TERRITÓRIO}

CANTUQUIRIGUAÇU (Condetec). Território Cantuquiriguaçu, Paraná: diagnóstico socioeconômico. Curitiba, 2004. Disponível em: < http:// www.iapar.br/arquivos/File/zip_pdf/cantuquiriguacu.pdf $>$.

DUARTE, Adriano L; RAMPINELLI, Waldir José. Universidade, sociedade e política: algumas considerações sobre a relação entre público e privado em tempos de barbárie. In: RAMPINELLI, Waldir José, ALVIM, Valdir; RODRIGUES, Gilmar. Universidade: a democracia ameaçada. São Paulo: Xamã, 2005.

FERNANDES, Bernardo Mançano. Entrando nos territórios do território. In: PAULINO, E.; FABRINI, J. E. (Orgs.). Campesinato e territórios em disputa. São Paulo: Expressão Popular, 2008. Disponível em: <http:// www2.fct.unesp.br/nera/artigodomes/3artigodomes_2008.pdf $>$.

FLEURI, Reinaldo Matias. Educação popular e universidade: contradições e perspectivas emergentes nas experiências de extensão universitária em educação popular na Universidade Estadual de Campinas - Unicamp (1978-1987). Florianópolis: NUP/CED/UFSC, 2001.

GADOTTI, Moacir. Pedagogia da práxis. São Paulo: Cortez, 1995.

KUENZER, Acácia Z. A educação profissional nos anos 2000: a dimensão subordinada das políticas de inclusão. Educação \& Sociedade, Campinas, v. 27, n. 96, p. 4, out. 2006. Disponível em: < http://www. scielo.br/pdf/es/v27n96/a12v2796.pdf>.

LIMA FILHO, Paulo Alves de et al. Notas introdutórias à questão do controle social na UFFS: preâmbulo a uma constituição. Cuadernos de Educación y Desarollo [on-line], Málaga, Espanha, v. 1, n. 9, nov. 2009. (Texto elaborado para discussão do Movimento Pró Universidade).

Disponível em: < http://www.eumed.net/rev/ced/09/palf.htm>.

OLIVEIRA, A. Marx e a exclusão. Pelotas: Seiva, 2004.

UNIVERSIDADE FEDERAL DA FRONTEIRA SUL (UFFS). Edital no 045/ UFFS/2011, de 3 de março de 2011. A Reitoria [...] torna pública a realização de processo seletivo para participação no Programa Bolsa de 
Estudos Orientados - 2011, mediante as condições estabelecidas neste edital. 2011.

. Edital no 162/UFFS/2011, de 8 de novembro de 2011.

Processo seletivo UFSS 2012. 2011.

. Perfil. In: . Sobre a UFFS. 2010a. Disponível em:

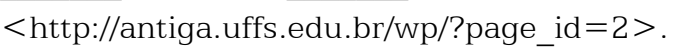

. Projeto pedagógico institucional. 2010b. Disponível em:

$<$ http://antiga.uffs.edu.br/wp/?page_id=83>.

. I Conferência de Ensino, Pesquisa e Extensão (Coepe):

construindo agendas e definindo rumos - documento base. Chapecó, SC, 2010c. Disponível em: < http://www.uffs.edu.br/images/proec/ COEPE_-_DOCUMENTO_BASE.pdf $>$.

Naira Estela Roesler Mohr, mestre em Educação pela Universidade Federal de Santa Catarina (UFSC), é professora do Curso de Pedagogia da Universidade Federal da Fronteira Sul (UFFS) - campus Erechim. nairamohr@uffs.edu.br

Felipe Mattos Monteiro, mestre em Sociologia Política pela Universidade Federal de Santa Catarina (UFSC), é professor da Universidade Federal da Fronteira Sul (UFFS) e membro do Núcleo Interdisciplinar em Políticas Públicas (NIPP-UFSC).

malttos@yahoo.com.br

Joaquim Gonçalves Costa, mestre em Educação pela Universidade Federal do Paraná (UFPR), é professor efetivo com dedicação exclusiva da Universidade Federal da Fronteira Sul/Campus Laranjeiras do SulParaná. É coordenador do Curso Interdisciplinar em Educação no CampoLicenciatura dessa universidade.

joaquim@uffs.edu.br

João Costa de Oliveira, licenciado em Filosofia, História e Sociologia pela Pontifícia Universidade Católica do Paraná (PUCPR), é especialista em Pensamento Latinoamericano (Filosofia da Libertação) pela Faculdade Espírita de Curitiba e professor de Filosofia da Rede Estadual de Ensino do Paraná.

joaocostapt@hotmail.com

Recebido em 20 de abril de 2011.

Aprovado em 18 de abril de 2012. 